\title{
Effectiveness of favipiravir in COVID-19: a live systematic review
}

\author{
Batu Özlüşen ${ }^{1} \cdot$ Şima Kozan ${ }^{1} \cdot$ Rüştü Emre Akcan ${ }^{1} \cdot$ Mekselina Kalender $^{1}$ • Doğukan Yaprak ${ }^{1}$. \\ İbrahim Batuhan Peltek ${ }^{1} \cdot$ Şiran Keske ${ }^{1,2} \cdot$ Mehmet Gönen $^{1,2,3} \cdot$ Önder Ergönül ${ }^{1,2}$
}

Received: 1 March 2021 / Accepted: 5 July 2021 / Published online: 4 August 2021

(C) The Author(s), under exclusive licence to Springer-Verlag GmbH Germany, part of Springer Nature 2021

\begin{abstract}
We performed a systematic review and meta-analysis for the effectiveness of Favipiravir on the fatality and the requirement of mechanical ventilation for the treatment of moderate to severe COVID-19 patients. We searched available literature and reported it by using PRISMA (Preferred Reporting Items for Systematic Reviews and Meta-Analyses) guidelines. Until June 1, 2021, we searched PubMed, bioRxiv, medRxiv, ClinicalTrials.gov, Cochrane Central Register of Controlled Trials (CENTRAL), and Google Scholar by using the keywords "Favipiravir" and terms synonymous with COVID-19. Studies for Favipiravir treatment compared to standard of care among moderate and severe COVID-19 patients were included. Risk of bias assessment was performed using Revised Cochrane risk of bias tool for randomized trials (RoB 2) and ROBINS-I assessment tool for non-randomized studies. We defined the outcome measures as fatality and requirement for mechanical ventilation. A total of 2702 studies were identified and 12 clinical trials with 1636 patients were analyzed. Nine out of 12 studies were randomized controlled trials. Among the randomized studies, one study has low risk of bias, six studies have moderate risk of bias, and 2 studies have high risk of bias. Observational studies were identified as having moderate risk of bias and nonrandomized study was found to have serious risk of bias. Our meta-analysis did not reveal any significant difference between the intervention and the comparator on fatality rate (OR 1.11, 95\% CI 0.64-1.94) and mechanical ventilation requirement (OR $0.50,95 \% \mathrm{CI} 0.13-1.95)$. There is no significant difference in fatality rate and mechanical ventilation requirement between Favipiravir treatment and the standard of care in moderate and severe COVID-19 patients.
\end{abstract}

Keywords Favipiravir · COVID-19 $\cdot$ Effectiveness $\cdot$ Meta-analysis $\cdot$ Systematic review

\section{Introduction}

SARS-CoV-2 with an extremely high spreading potential caused a global crisis with significant bottleneck in diagnosis, treatment, and prevention. Despite the active search for an effective and definitive cure, there is no specific antiviral drug identified for the treatment of COVID-19 yet; this has been one of the most challenging aspects of the pandemic. Repurposing of existing antiviral agents against COVID-19 became the common approach to treatment [1].

Önder Ergönül

oergonul@ku.edu.tr

School of Medicine, Koç University, Istanbul, Turkey

2 Koç University İşBank Center for Infectious Diseases (KUISCID), Istanbul, Turkey

3 Department of Industrial Engineering, College of Engineering, Koç University, Istanbul, Turkey
Favipiravir, one of these repurposed drugs, is an antiviral agent targeting and competitively inhibiting viral RNAdependent RNA polymerase; it is approved in Japan for the treatment of influenza [2]. In some countries, Favipiravir is still in use for the treatment of SARS-CoV-2; however, there is no consensus on its effectiveness in treatment of COVID-19 yet. Therefore, we aim to review the published data regarding the use of Favipiravir in moderate and severe COVID-19 patients. Our live systematic review system will allow the addition of the new findings and provide the results promptly.

\section{Methodology}

\section{Search strategy}

We systematically reviewed the available literature and presented it using PRISMA (Preferred Reporting Items 
for Systematic Reviews and Meta-Analyses) guidelines [3]. Until June 1, 2021, we searched the following sources using the keywords "Favipiravir" and terms synonymous with COVID-19: PubMed, bioRxiv, medRxiv, ClinicalTrials.gov, Cochrane Central Register of Controlled Trials (CENTRAL), and Google Scholar.

We included randomized and observational clinical trials that were conducted to investigate the effectiveness of Favipiravir for COVID-19 patients. Studies comparing Favipiravir versus standard of care; different dosages of Favipiravir versus each other; Favipiravir in combination with ineffective agents versus Favipiravir alone were eligible. We avoided gray literature, case series and observational studies without control groups, and randomization. Eventual decision whether or not to include the study in the systematic review was given by two principal investigators in consideration of eligibility criteria. We included the studies with moderate and severe patients, and excluded the ones with critical patients according to the WHO guidelines [4].

\section{Data abstraction and risk of bias assessment}

Investigators abstracted data about study design, intervention type, population of control and experimental groups, the stage of the clinical condition, and outcome measures on a Microsoft Excel file. Risk of bias assessment was carried out using Revised Cochrane risk of bias tool for randomized trials (RoB 2) [5] and ROBINS-I assessment tool for nonrandomized studies [6]. RoB 2 consists of the following five components: risk of bias arising from the randomization process, bias due to deviations from the intended interventions, bias due to missing outcome data, bias in measurement of the outcome, and bias in selection of the reported result. We defined the low risk of bias, if all components of the tool were rated as low. ROBINS-I is composed of seven components: bias due to confounding, bias in selection of participants into the study, bias in classification of interventions, bias due to deviations from intended interventions, bias due to missing data, bias in measurement of outcomes, and bias in selection of the reported result. All components must be rated as at low risk of bias for overall study to be at low risk. If there is not any component with serious or critical risk, moderate risk in at least one component is enough to rate the study as at moderate risk of bias.

\section{Data analysis}

Primary outcome measures were defined as fatality rates and requirement of ventilation in moderate and severe COVID19 patients. Heterogeneity assessment was done using the I-squared $\left(\mathrm{I}^{2}\right)$ test. For outcome estimation, odds ratio is calculated whenever appropriate with $95 \%$ Confidence Interval (CI). Fixed and random effect models were used. Forest plot was used to visualize outcome estimation. As new results come out from the upcoming clinical trials, they will be included in our live meta-analysis.

\section{Results}

We identified 2702 studies with our keywords, 2420 studies directly from database search, and 282 studies from other sources such as bioRxiv and medRxiv. After removing 1193 duplicates, we screened titles and abstracts of 1509 studies. Overall, 88 studies were chosen for further analysis, and 1421 studies were excluded due to irrelevant content. We assessed full-text articles of 88 studies for eligibility and included 12 articles in quantitative synthesis (Fig. 1).

\section{Overview of randomized results}

Risk of bias assessment of the included studies was reported in Table 1. Among the randomized studies, one study [7] has low risk, six studies [8-14] have moderate risk, and two studies $[15,16]$ have high risk. Observational studies $[14,17]$ are identified as moderate risk, and nonrandomized study [18] is found to have serious risk.

When studies were investigated from intervention and comparator perspective, two trials compared $1600 \mathrm{mg}$ or $1800 \mathrm{mg}$ of Favipiravir with a patient group treated according to the Russian guidelines $[8,11]$. Three trials compared Favipiravir with standard supportive care and one of these administered other antiviral medications outside of Favipiravir [14, 16, 17]. Three trials compared Favipiravir with Hydroxychloroquine [7, 9, 13], one compared with Chloroquine [12], two compared with Lopinavir/Ritonavir [10, 18], and one compared with Umifenovir (Arbidol) [15]. Favipiravir was used in varying doses (Table 2). In all studies, the proportion of male patients was higher. The mean age usually was below the age of 65 . According to patients' baseline severity characteristics, four studies $[8,11,13,18]$ included only moderate patients. Three studies $[7,12,16]$ included mild-to-moderate patients, and five studies $[9,10,14,15$, 17] included moderate-to-severe patients.

We performed two meta-analyses for the effectiveness of Favipiravir administration on moderate and severe COVID19 patients, one on mortality rates by comparing the intervention and comparator groups and one on the requirement of mechanical ventilation by comparing the intervention and comparator groups. In the meta-analysis on fatality rates, only seven studies were suitable for odds ratio calculation (OR 1.11, 95\% CI 0.64-1.94). No heterogeneity was detected among these studies $\left(\mathrm{I}^{2}=0 \%, \tau^{2}=0 ; \mathrm{p}=0.69\right)$ (Fig. 2).

Secondly, we performed a meta-analysis on the requirement of mechanical ventilation, the odds ratio could 
Fig. 1 Search strategy
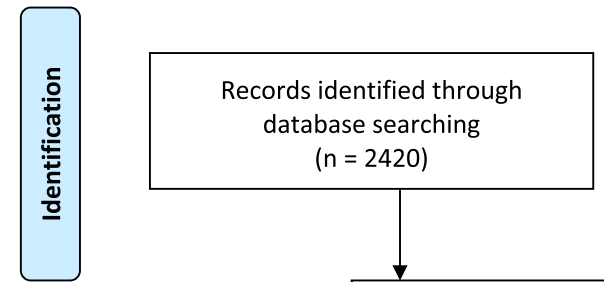

Additional records identified through other sources $(n=2420)$

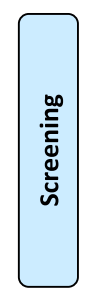

Records after duplicates removed $(n=1509)$
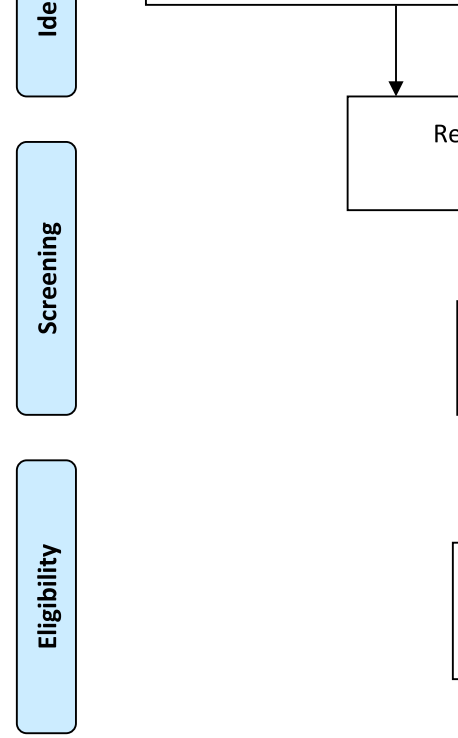

( $n=282$, bioRxiv $=116$, edRxiv $=166)$
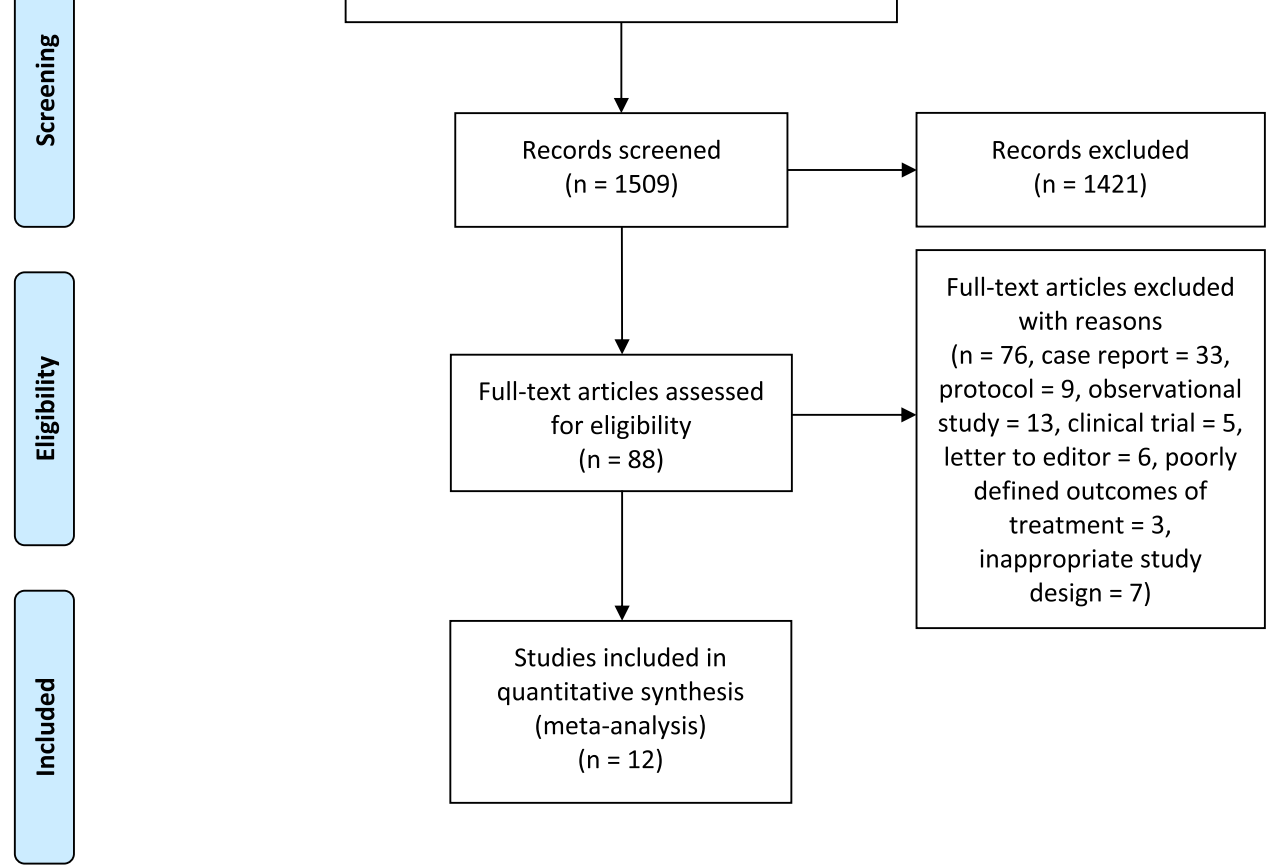

Full-text articles excluded with reasons ( $n=76$, case report $=33$, protocol $=9$, observational study $=13$, clinical trial $=5$, letter to editor $=6$, poorly defined outcomes of treatment $=3$, inappropriate study design =7)

Table 1 Risk assessment

\begin{tabular}{|c|c|c|c|}
\hline Study, year (reference) & Study type; risk of bias & Participants, $\mathrm{n}$ & Country \\
\hline Ivashchenko et al., 2020 [8] & Open label; moderate risk of bias & 60 & Russia \\
\hline Pushkar et al., 2020 [11] & Open label; moderate risk of bias & 200 & Russia \\
\hline Udwadia et al., 2020 [16] & Open label, randomized; high risk of bias & 150 & India \\
\hline Khamis et al., 2020 [9] & Open label, randomized; moderate risk of bias & 89 & Oman \\
\hline Lou et al., $2020[10]$ & Open label; moderate risk of bias & 20 & China \\
\hline Chen et al., 2020 [15] & Open label, randomized; high risk of bias & 240 & China \\
\hline Szabo et al., 2020 [17] & Observational; moderate risk of bias & 150 & Hungary \\
\hline Cai et al., $2020[18]$ & Open label, non-randomized; serious risk of bias & 80 & China \\
\hline Dabbous et al., 2021a [12] & Open label; moderate risk of bias & 92 & Egypt \\
\hline Dabbous et al., 2021b [7] & Open label; low risk of bias & 100 & Egypt \\
\hline Balykova et al., 2020 [13] & Open label; moderate risk of bias & 39 & Russia \\
\hline Alamer et al., 2021 [14] & Observational; moderate risk of bias & 416 & Saudi Arabia \\
\hline
\end{tabular}

be calculated for only five studies (OR $0.50,95 \%$ CI $0.13-1.95)$. The heterogeneity of these studies was significant $\left(\mathrm{I}^{2}=75 \%, \tau^{2}=1.5665 ; \mathrm{p}<0.01\right)$ (Fig. 3$)$.

\section{Discussion}

Our meta-analysis was focused on two primary outcomes: the effect of Favipiravir on fatality and mechanical 


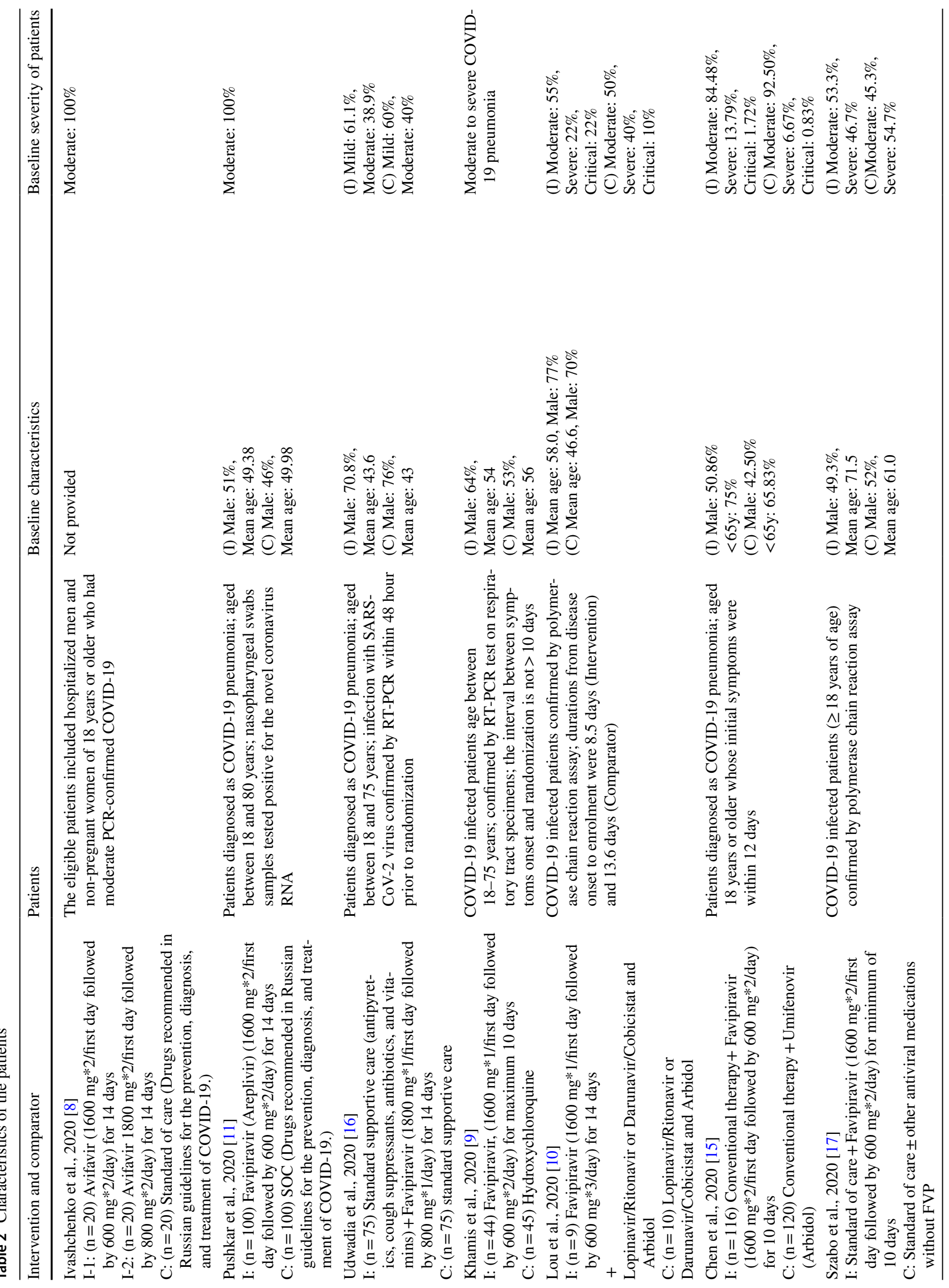




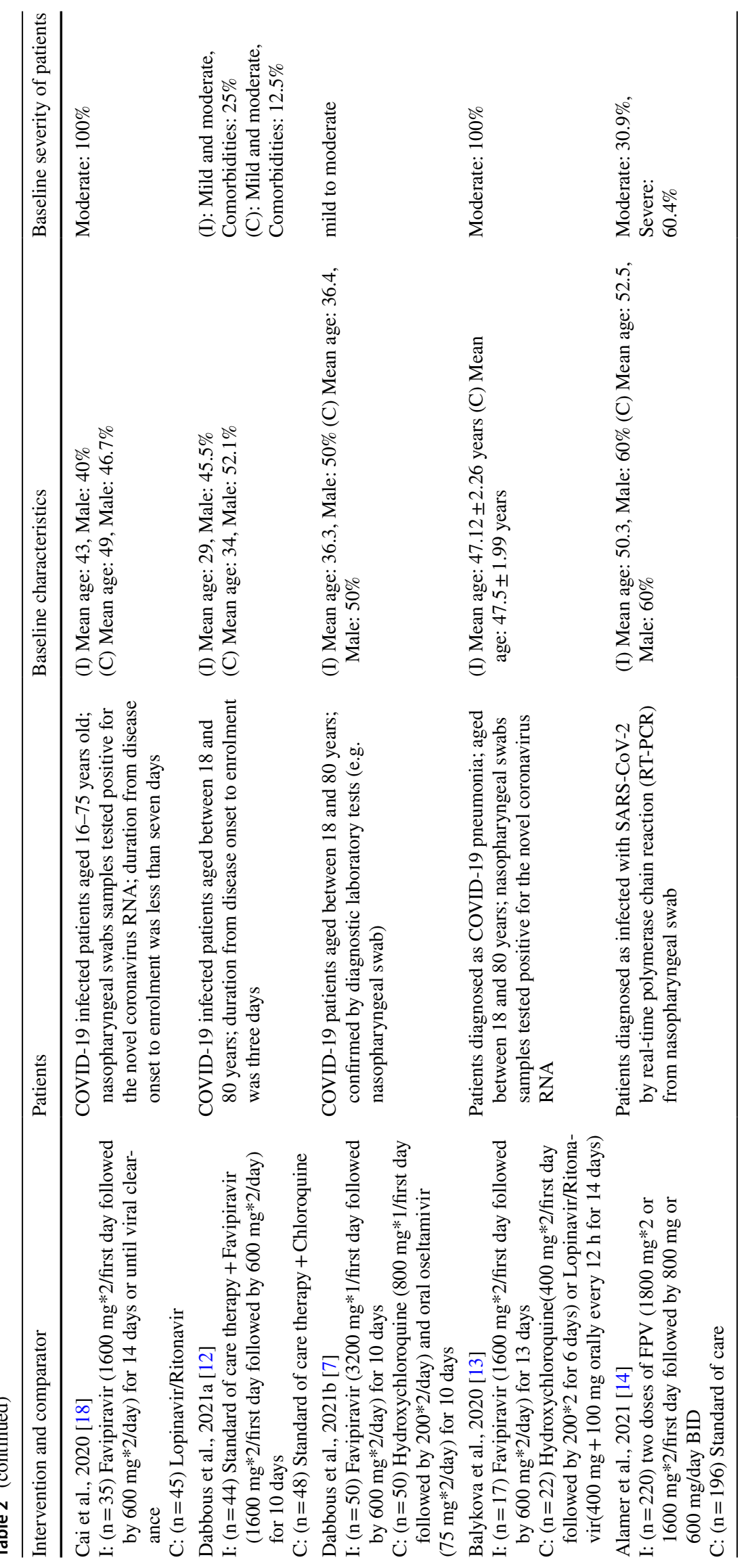


Fig. 2 Forest plot for the effectiveness of Favipiravir on fatality compared to standard of care

\begin{tabular}{lrr} 
& \multicolumn{2}{c}{ Favipiravir } \\
Study & Fatal & Total \\
Ivashchenko et al. (2020) & 2 & 40 \\
Pushkar et al. (2020) & 0 & 100 \\
Udwadia et al. (2021) & 0 & 75 \\
Khamis et al. (2021) & 5 & 44 \\
Lou et al. (2021) & 0 & 7 \\
Chen et al. (2020) & 0 & 116 \\
Szabo et al. (2020) & 9 & 75 \\
Cai et al. (2020) & 0 & 35 \\
Dabbous et al. (2021a) & 1 & 44 \\
Dabbous et al. (2021b) & 0 & 50 \\
Balykova et al. (2020) & 0 & 17 \\
Alamer et al. (2021) & 14 & 220 \\
Fixed effect model & & \\
Random effects model & & $\mathbf{8 2 3}$ \\
Heterogeneity: $l^{2}=0 \%, \tau^{2}=0, p=0.69$ &
\end{tabular}

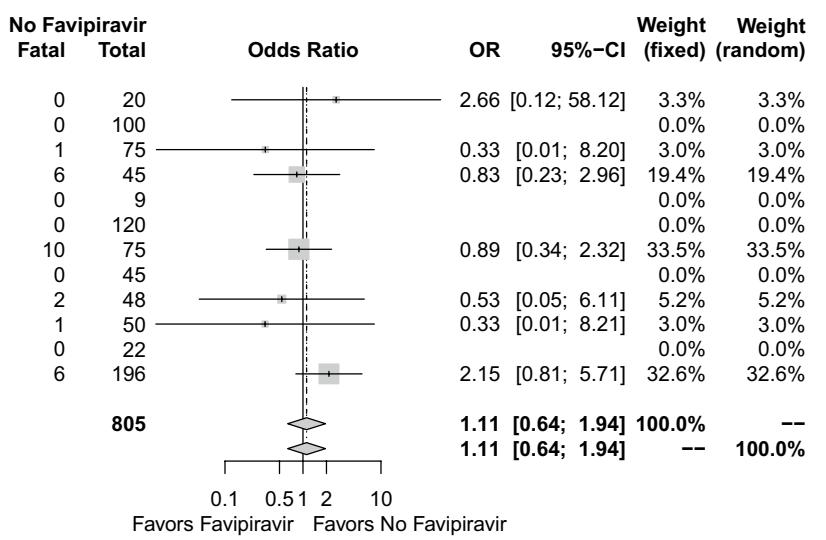

Fig. 3 Forest plot for the effectiveness of Favipiravir on the need for mechanic ventilation compared to standard of care

\begin{tabular}{lrr} 
& \multicolumn{2}{c}{ Favipiravir } \\
Study & Ventilation & Total \\
& & \\
Ivashchenko et al. (2020) & 2 & 40 \\
Pushkar et al. (2020) & 0 & 100 \\
Lou et al. (2021) & 0 & 7 \\
Chen et al. (2020) & 21 & 116 \\
Szabo et al. (2020) & 8 & 75 \\
Dabbous et al. (2021a) & 0 & 44 \\
Balykova et al. (2020) & 0 & 17 \\
Alamer et al. (2021) & 2 & 220 \\
& & \\
Fixed effect model & & 619 \\
Random effects model & & \\
Heterogeneity: $I^{2}=75 \%, \tau^{2}=1.5665, p<0.01$ &
\end{tabular}

ventilation. Our findings revealed that Favipiravir, for up to 14 days, has no superiority over standard of care or other antivirals that are previously shown to be ineffective for COVID-19 such as hydroxychloroquine [19, 20], chloroquine [21], Lopinavir/Ritonavir [22], and Arbidol [23] (Figs. 2 and 3). Notably, in the meta-analysis for mechanical ventilation, we detected significant heterogeneity, which indicates the diversity of clinical studies included. This finding is in favor of our report of moderate to high risk of bias in these studies.

All of our selected studies except Dabbous et al. [7] were identified as either moderate or high risk of bias. Having moderate or high risk of bias was the major limitation for the studies included, however we included all the available reports.

In vitro effectiveness of Favipiravir against SARS-CoV-2 is controversial. Wang et al. [24] reported an EC50 value of $61.88 \mu \mathrm{M}$ for the antiviral activity of Favipiravir, while results from Pizzorno et al. [25] and Choy et al. [26] showed no inhibition at $100 \mu \mathrm{M}$, which was the highest concentration tested in an antiviral assay. Results from Lou et al. [10] showed that less than $50 \%$ of SARS-CoV-2 had been affected in vitro at Favipiravir concentrations up to $100 \mu \mathrm{M}$. Moreover, the intracellular concentration of the active metabolite determines the efficacy of Favipiravir in patients [27]. In vivo intracellular simulations conducted by Pertinez et al. [28] indicated that a loading dose of $1600 \mathrm{mg}$ twice daily on day 1 followed by a maintenance dose of $1200 \mathrm{mg}$ twice daily for nine days could reach the therapeutic concentrations of the intracellular active metabolite of Favipiravir. However, further studies are needed for pharmacokinetics of Favipiravir.

Although, at the beginning of the pandemic, it was believed that viral load measurements and viral clearance were appropriate to follow disease progress in COVID19 patients [23], learning more about SARS-CoV-2 has shown that viral load as an outcome is not a good choice to measure the treatment efficacy. Many patients continued to have positive RNA tests, even after they have unequivocally recovered [29]. As a result, CDC has updated the definition of recovery as being symptom-free for over $24 \mathrm{~h}$ after symptom onset [30]. Therefore, we think that viral load measurements would not be a proper indicator of the effectiveness of Favipiravir, and we did not include it in our meta-analysis. Subsequently, we did not include the clinical improvement data in our meta-analysis, because the definition of this concept differs among studies and leaves the clinical improvement being a subjective concept. However, incorporating a brief overview of findings regarding the viral clearance and the clinical improvement into the discussion part could be beneficial. Seven studies have reported viral clearance as an outcome, but there are some methodological differences between them in the assessment of viral clearance. Ivashchenko et al. [8] and Pushkar et al. [11] found that viral clearance is higher in the Favipiravir group at day 10. Lou et al. [10] found that viral clearance was higher 
in the Favipiravir group on day 14. Additionally, Udwadia et al. [16] and Cai et al. [18] found that median days for viral clearance was lower in Favipiravir group than control, showing that the viral clearance was better with Favipiravir treatment. Balykova et al. [13] found no significant difference between control and Favipiravir group in viral clearance since all patients were negative at day 10. On the other hand, Szabo et al. [17] found that median days for viral clearance was higher in the Favipiravir group indicating that Favipiravir does not have any significant effect on viral clearance. According to the study of Zhao et al. [31] conducted on patients with SARS-CoV-2 re-positive after discharge, the Favipiravir group experienced faster viral clearance than the control group. Four studies $[8,11,13$, 18] have investigated the improvement rates of chest CT scans. Ivashchenko et al. [8] and Pushkar et al. [11] reported that there was no significant difference between Favipiravir and control arm in terms of chest CT improvement on day 15. Balykova et al. [13] and Cai et al. [18] reported that the improvement rates of the chest $\mathrm{CT}$ changes were higher in the Favipiravir arm on day 15. Four studies [8, 11, 13, 15] investigated body temperature normalization. Chen et al. [15], Blaykova et al. [13], and Ivashchenko et al. [8] found that the time to pyrexia relief was shorter in the Favipiravir arm. However, Pushkar et al. [11] found that there is not a significant difference between Favipiravir and control arm in terms of body temperature recovery time. Four studies [10, $11,15,16]$ investigated clinical improvement. On day 14, clinical improvement was not significantly different between Favipiravir and the control arm according to Udwadia et al. [16] and Lou et al. [10]. Pushkar et al. [11] and Chen et al. [15] found that clinical status improvement rate was significantly higher in the Favipiravir group on day 14 and day 7 , respectively.

We excluded the studies that compared the critical patients who stayed in ICU, because the effect of antivirals can be seen at the first week of the disease. Relatedly, we did not include the duration of stay in the intensive care unit (ICU) in the analysis. Nevertheless, summarizing the findings related to critical patients could give an insight into the effectiveness of Favipiravir in those patients. In the study of Lou et al. [10], there were two critical patients in the Favipiravir group and one critical patient in the control group. Although the patient in the control group and one of the patients in the Favipiravir group had viral clearance in 14 days, the other patient in the Favipiravir group could not turn viral negative in 14 days. Alamer et al. [14] compared the mortality and median time to discharge among critical patients in Favipiravir and control groups. The median time to discharge is 21 and 32 in Favipiravir and control groups, respectively. Whereas the fatality rates are given as $46.2 \%$ in the Favipiravir group and $25.9 \%$ in the control group. Takahashi et al. [32] reported two critical patients, who started
Favipiravir on day 11 after symptom onset. Patients turned viral negative in 18 and 13 days, respectively, and experienced chest imaging improvement.

There are several limitations of our analysis. The scarcity of the randomized clinical trials narrows the sample size of our analysis. Moreover, it is hard to conduct a large-scale clinical trial in this pandemic due to the lack of patients without any previous treatment. Some observational studies are not prospective while some clinical trials are not controlled. In our analysis, all clinical trials are open label and one of them is not a randomized study. Another limitation was the variation in the definitions of patient severity. In two studies, few critical patients were included. In Lou et al. [10], results of critical patients were removed but it was not feasible to separate the data of critical patients in Chen et al. [15]. We did not exclude it since the percentage of critical patients was very limited (Table 2). There is heterogeneity in the control groups and there is no study done against placebo. Nevertheless, drugs used in control groups are proven not to be effective against COVID-19. Risk factors that can increase mortality rate are not specified in some studies. Results of this meta-analysis cannot be applied to patients with severe renal or hepatic dysfunction and pregnant women because they were not included in clinical trials and the observational study.

In some countries, COVID-19 treatment guidelines suggested Favipiravir as an antiviral drug proven to be safe and effective in vitro. Based on published data and literature, the countries that use Favipiravir are China, Hungary, India, Korea, Poland, Portugal, Russia, Serbia, Thailand, and Turkey. By June 1, 2021, 52 active trials in countries including Italy, Saudi Arabia, Indonesia, Kuwait, USA, Iran, Nepal, Canada, Bahrain, Egypt, UK, Thailand, Australia, South Africa, and Germany were registered in clinicaltrial. gov [33]. Among these studies, 13 of them had a completed status, and one completed study with published results has been included in this meta-analysis. In a recent meta-analysis performed for the effectiveness of Favipiravir, the authors [34] reported that Favipiravir had no significant beneficial effect on the mortality among mild to moderate COVID-19 patients. The authors stated that the late administration of antivirals could explain their low effectiveness. However, in some countries e.g. Turkey, Favipiravir is provided by the Ministry of Health and administered early in the disease course and no significant benefit has been reported yet.

\section{Conclusion}

There is no evidence that Favipiravir decreases the fatality rate or the use of mechanical ventilation among moderate and severe patients with COVID-19. Randomized clinical trials or quality observational studies including moderate 
and severe patients with appropriate sample sizes are needed for describing the effectiveness of Favipiravir in COVID-19.

Acknowledgements We are thankful to Ertaç Nebioğlu from Koç University Health Sciences Library for his effort on systematic literature search.

Author contribution Literature search: BÖ, ŞKo, REA, MK, DY, İBP, ŞKe, ÖE.

Data analysis: BÖ, ŞKo, REA, MK, DY, İBP, ŞKe, MG, ÖE

Manuscript writing: BÖ, ŞKo, REA, MK, DY, İBP, ŞKe, MG, ÖE

Data availability All the data for analysis is available.

Code availability The codes of the software application $(\mathrm{R})$ are available.

\section{Declarations}

Ethics approval and consent to participate The analysis of systematic review is exempt from IRB review.

Conflict of interest The authors declare no competing interests.

\section{References}

1. Consortium WHOST, Pan H, Peto R, Henao-Restrepo AM, Preziosi MP, Sathiyamoorthy V, Abdool Karim Q, Alejandria MM, Hernandez Garcia C, Kieny MP, Malekzadeh R, Murthy S, Reddy KS, Roses Periago M, Abi Hanna P, Ader F, Al-Bader AM, Alhasawi A, Allum E, Alotaibi A, Alvarez-Moreno CA, Appadoo S, Asiri A, Aukrust P, Barratt-Due A, Bellani S, Branca M, Cappel-Porter HBC, Cerrato N, Chow TS, Como N, Eustace J, Garcia PJ, Godbole S, Gotuzzo E, Griskevicius L, Hamra R, Hassan M, Hassany M, Hutton D, Irmansyah I, Jancoriene L, Kirwan J, Kumar S, Lennon P, Lopardo G, Lydon P, Magrini N, Maguire T, Manevska S, Manuel O, McGinty S, Medina MT, Mesa Rubio ML, Miranda-Montoya MC, Nel J, Nunes EP, Perola M, Portoles A, Rasmin MR, Raza A, Rees H, Reges PPS, Rogers CA, Salami K, Salvadori MI, Sinani N, Sterne JAC, Stevanovikj M, Tacconelli E, Tikkinen KAO, Trelle S, Zaid H, Rottingen JA, Swaminathan S (2020) Repurposed Antiviral Drugs for Covid-19 - Interim WHO Solidarity Trial Results. N Engl J Med. https://doi.org/10.1056/ NEJMoa2023184

2. Furuta Y, Gowen BB, Takahashi K, Shiraki K, Smee DF, Barnard DL (2013) Favipiravir (T-705), a novel viral RNA polymerase inhibitor. Antiviral Res 100(2):446-454. https://doi.org/10.1016/j. antiviral.2013.09.015

3. Liberati A, Altman DG, Tetzlaff J, Mulrow C, Gotzsche PC, Ioannidis JP, Clarke M, Devereaux PJ, Kleijnen J, Moher D (2009) The PRISMA statement for reporting systematic reviews and metaanalyses of studies that evaluate health care interventions: explanation and elaboration. Ann Intern Med 151(4):W65-94. https:// doi.org/10.7326/0003-4819-151-4-200908180-00136

4. WHO (2021) Report of the WHO-China Joint Mission on Coronavirus Disease 2019 (COVID-19). https://www.who.int/docs/ default-source/coronaviruse/who-china-joint-mission-on-covid19-final-report.pdf. Accessed 5 June 2021

5. Sterne JAC, Savovic J, Page MJ, Elbers RG, Blencowe NS, Boutron I, Cates CJ, Cheng HY, Corbett MS, Eldridge SM, Emberson JR, Hernan MA, Hopewell S, Hrobjartsson
A, Junqueira DR, Juni P, Kirkham JJ, Lasserson T, Li T, McAleenan A, Reeves BC, Shepperd S, Shrier I, Stewart LA, Tilling K, White IR, Whiting PF, Higgins JPT (2019) RoB 2: a revised tool for assessing risk of bias in randomised trials. BMJ 366:14898. https://doi.org/10.1136/bmj.14898

6. Sterne JA, Hernan MA, Reeves BC, Savovic J, Berkman ND, Viswanathan M, Henry D, Altman DG, Ansari MT, Boutron I, Carpenter JR, Chan AW, Churchill R, Deeks JJ, Hrobjartsson A, Kirkham J, Juni P, Loke YK, Pigott TD, Ramsay CR, Regidor D, Rothstein HR, Sandhu L, Santaguida PL, Schunemann HJ, Shea B, Shrier I, Tugwell P, Turner L, Valentine JC, Waddington H, Waters E, Wells GA, Whiting PF, Higgins JP (2016) ROBINS-I: a tool for assessing risk of bias in non-randomised studies of interventions. BMJ 355:i4919. https://doi.org/10. 1136/bmj.i4919

7. Dabbous HM, El-Sayed MH, El Assal G, Elghazaly H, Ebeid FFS, Sherief AF, Elgaafary M, Fawzy E, Hassany SM, Riad AR, TagelDin MA (2021) Safety and efficacy of favipiravir versus hydroxychloroquine in management of COVID-19: a randomised controlled trial. Sci Rep 11(1):7282. https://doi.org/10.1038/ s41598-021-85227-0

8. Ivashchenko AA, Dmitriev KA, Vostokova NV, Azarova VN, Blinow AA, Egorova AN, Gordeev IG, Ilin AP, Karapetian RN, Kravchenko DV et al (2020) AVIFAVIR for Treatment of patients with moderate COVID-19: interim results of a Phase II/III Multicenter Randomized Clinical Trial. Clin Infect Dis. https://doi.org/ 10.1093/cid/ciaa1176

9. Khamis F, Al Naabi H, Al Lawati A, Ambusaidi Z, Al Sharji M, Al Barwani U, Pandak N, Al Balushi Z, Al Bahrani M, Al Salami I, Al-Zakwani I (2021) Randomized controlled open label trial on the use of favipiravir combined with inhaled interferon beta- $1 \mathrm{~b}$ in hospitalized patients with moderate to severe COVID-19 pneumonia. Int J Infect Dis 102:538-543. https://doi.org/10.1016/j.ijid. 2020.11.008

10. Lou Y, Liu L, Yao H, Hu X, Su J, Xu K, Luo R, Yang X, He L, Lu X, Zhao Q, Liang T, Qiu Y (2021) Clinical outcomes and plasma concentrations of baloxavir marboxil and favipiravir in COVID-19 patients: an exploratory randomized, controlled trial. Eur J Pharm Sci 157:105631. https://doi.org/10.1016/j.ejps.2020.105631

11. Pushkar D (2020) Study of Favipiravir Compared to Standard of Care in Hospitalized Patients With COVID-19. https://www. clinicaltrials.gov/ct2/show/results/NCT04542694?term=Favip iravir\&recrs $=e \&$ cond $=$ COVID $\&$ draw $=2 \&$ rank $=1$. Accessed 25 Dec 2020

12. Dabbous HM, Abd-Elsalam S, El-Sayed MH, Sherief AF, Ebeid FFS, El Ghafar MSA, Soliman S, Elbahnasawy M, Badawi R, Tageldin MA (2021) Efficacy of favipiravir in COVID-19 treatment: a multi-center randomized study. Arch Virol 166(3):949954. https://doi.org/10.1007/s00705-021-04956-9

13. Balykova LA, Pavelkina VF, Shmyreva NV, Pyataev NA, Selezneva NM, Shepeleva OI, Almyasheva RZ (2020) Efficacy and safety of some etiotropic therapeutic schemes for treating patients with novel coronavirus infection (COVID-19). Pharm Pharmacol 8(3):150-159. https://doi.org/10.19163/ 2307-9266-2020-8-3-150-159

14. Alamer A, Alrashed AA, Alfaifi M, Alosaimi B, AlHassar F, Almutairi M, Howaidi J, Almutairi W, Mohzari Y, Sulaiman T, Al-Jedai A, Alajami HN, Alkharji F, Alsaeed A, Alali AH, Baredhwan AA, Abraham I, Almulhim AS (2021) Effectiveness and safety of favipiravir compared to supportive care in moderately to critically ill COVID-19 patients: a retrospective study with propensity score matching sensitivity analysis. Curr Med Res Opin:1-13. https://doi.org/10.1080/03007995.2021.1920900

15. Chen C, Zhang Y, Huang J, Yin P, Cheng Z, Wu J, Chen S, Zhang Y, Chen B, Lu M, Luo Y, Ju L, Zhang J, Wang X (2020) Favipiravir versus Arbidol for COVID-19: a randomized clinical trial. med 
Rxiv:2020.2003.2017.20037432. https://doi.org/10.1101/2020.03. 17.20037432

16. Udwadia ZF, Singh P, Barkate H, Patil S, Rangwala S, Pendse A, Kadam J, Wu W, Caracta CF, Tandon M (2020) Efficacy and safety of favipiravir, an oral RNA-dependent RNA polymerase inhibitor, in mild-to-moderate COVID-19: a randomized, comparative, open-label, multicenter, phase 3 clinical trial. Int J Infect Dis 103:62-71. https://doi.org/10.1016/j.ijid.2020.11.142

17. Szabo BG, Lenart KS, Petrik B, Gaspar Z, Balogh Z, Banyai Z, Banyasz E, Budai J, Czel E, Fried K, Hanuska A, Kiss-Dala N, Lorinczi C, Nemesi K, Kadar J, Nagy EL, Osvald A, Petrovicz E, Riczu A, Szanka J, Szathmary B, Szombati A, Toth S, Varnai Z, Woller O, Szlavik J, Lakatos B (2020) Role of favipiravir in the treatment of adult patients with moderate to severe COVID-19: a single-center, prospective, observational, sequential cohort study from Hungary. medRxiv:2020.2011.2026.20238014. https://doi. org/10.1101/2020.11.26.20238014

18. Cai Q, Yang M, Liu D, Chen J, Shu D, Xia J, Liao X, Gu Y, Cai Q, Yang Y, Shen C, Li X, Peng L, Huang D, Zhang J, Zhang S, Wang F, Liu J, Chen L, Chen S, Wang Z, Zhang Z, Cao R, Zhong W, Liu Y, Liu L (2020) Experimental treatment with favipiravir for COVID-19: an open-label control study. Engineering (Beijing) 6(10):1192-1198. https://doi.org/10.1016/j.eng.2020.03.007

19. Geleris J, Sun Y, Platt J, Zucker J, Baldwin M, Hripcsak G, Labella A, Manson DK, Kubin C, Barr RG, Sobieszczyk ME, Schluger NW (2020) Observational study of hydroxychloroquine in hospitalized patients with Covid-19. N Engl J Med 382(25):2411-2418. https://doi.org/10.1056/NEJMoa2012410

20. Tang W, Cao Z, Han M, Wang Z, Chen J, Sun W, Wu Y, Xiao W, Liu S, Chen E, Chen W, Wang X, Yang J, Lin J, Zhao Q, Yan Y, Xie Z, Li D, Yang Y, Liu L, Qu J, Ning G, Shi G, Xie Q (2020) Hydroxychloroquine in patients with mainly mild to moderate coronavirus disease 2019: open label, randomised controlled trial. BMJ 369:m1849. https://doi.org/10.1136/bmj.m1849

21. Kashour Z, Riaz M, Garbati MA, AlDosary O, Tlayjeh H, Gerberi D, Murad MH, Sohail MR, Kashour T, Tleyjeh IM (2021) Efficacy of chloroquine or hydroxychloroquine in COVID-19 patients: a systematic review and meta-analysis. J Antimicrob Chemother 76(1):30-42. https://doi.org/10.1093/jac/dkaa403

22. Cao B, Wang Y, Wen D, Liu W, Wang J, Fan G, Ruan L, Song B, Cai Y, Wei M, Li X, Xia J, Chen N, Xiang J, Yu T, Bai T, Xie X, Zhang L, Li C, Yuan Y, Chen H, Li H, Huang H, Tu S, Gong F, Liu Y, Wei Y, Dong C, Zhou F, Gu X, Xu J, Liu Z, Zhang Y, Li H, Shang L, Wang K, Li K, Zhou X, Dong X, Qu Z, Lu S, Hu X, Ruan S, Luo S, Wu J, Peng L, Cheng F, Pan L, Zou J, Jia C, Wang J, Liu X, Wang S, Wu X, Ge Q, He J, Zhan H, Qiu F, Guo L, Huang C, Jaki T, Hayden FG, Horby PW, Zhang D, Wang C (2020) A trial of lopinavir-ritonavir in adults hospitalized with severe Covid-19. N Engl J Med 382(19):1787-1799. https://doi. org/10.1056/NEJMoa2001282

23. Li Y, Xie Z, Lin W, Cai W, Wen C, Guan Y, Mo X, Wang J, Wang Y, Peng P, Chen X, Hong W, Xiao G, Liu J, Zhang L, Hu F, Li F, Zhang F, Deng X, Li L (2020) Efficacy and safety of lopinavir/ ritonavir or arbidol in adult patients with mild/moderate COVID19: an exploratory randomized controlled trial. Med 1(1):105-113. e104. https://doi.org/10.1016/j.medj.2020.04.001

24. Wang M, Cao R, Zhang L, Yang X, Liu J, Xu M, Shi Z, Hu Z, Zhong W, Xiao G (2020) Remdesivir and chloroquine effectively inhibit the recently emerged novel coronavirus (2019-nCoV) in vitro. Cell Res 30(3):269-271. https://doi.org/10.1038/ s41422-020-0282-0

25. Pizzorno A, Padey B, Dubois J, Julien T, Traversier A, Dulière V, Brun P, Lina B, Rosa-Calatrava M, Terrier O (2020) In vitro evaluation of antiviral activity of single and combined repurposable drugs against SARS-CoV-2. Antiviral Res 181:104878. https:// doi.org/10.1016/j.antiviral.2020.104878

26. Choy KT, Wong AY, Kaewpreedee P, Sia SF, Chen D, Hui KPY, Chu DKW, Chan MCW, Cheung PP, Huang X, Peiris M, Yen HL (2020) Remdesivir, lopinavir, emetine, and homoharringtonine inhibit SARS-CoV-2 replication in vitro. Antiviral Res 178:104786. https://doi.org/10.1016/j.antiviral.2020.104786

27. Bazzoli C, Jullien V, Le Tiec C, Rey E, Mentré F, Taburet AM (2010) Intracellular pharmacokinetics of antiretroviral drugs in HIV-infected patients, and their correlation with drug action. Clin Pharmacokinet 49(1):17-45. https://doi.org/10.2165/11318110000000000-00000

28. Pertinez H, Rajoli RKR, Khoo SH, Owen A (2021) Pharmacokinetic modelling to estimate intracellular favipiravir ribofuranosyl5 '-triphosphate exposure to support posology for SARS-CoV-2. medRxiv:2021.2001.2003.21249159. https://doi.org/10.1101/ 2021.01.03.21249159

29. Lan L, Xu D, Ye G, Xia C, Wang S, Li Y, Xu H (2020) Positive RT-PCR test results in patients recovered from COVID-19. JAMA 323(15):1502-1503. https://doi.org/10.1001/jama.2020.2783

30. CDC (2021) Interim guidance on ending isolation and precautions for adults with COVID-19. https://www.cdc.gov/coronavirus/ 2019-ncov/hcp/duration-isolation.html. Accessed 5 Jan 2021

31. Zhao H, Zhang C, Zhu Q, Chen X, Chen G, Sun W, Xiao Z, Du W, Yao J, Li G, Ji Y, Li N, Jiang Y, Wang Y, Zeng Q, Li W, Gong B, Chang X, Zhu F, Jiang X, Li J, Wu Z, Liu Y, Peng P, Wang G (2021) Favipiravir in the treatment of patients with SARS-CoV-2 RNA recurrent positive after discharge: a multicenter, open-label, randomized trial. Int Immunopharmacol 97:107702. https://doi. org/10.1016/j.intimp.2021.107702

32. Takahashi H, Iwasaki $\mathrm{Y}$, Watanabe $\mathrm{T}$, Ichinose $\mathrm{N}$, Okada $\mathrm{Y}$, Oiwa A, Kobayashi T, Moriya M, Oda T (2020) Case studies of SARS$\mathrm{CoV}-2$ treated with favipiravir among patients in critical or severe condition. Int J Infect Dis 100:283-285. https://doi.org/10.1016/j. ijid.2020.08.047

33. NIH (2021) ClinicalTrials.gov. https://clinicaltrials.gov/ct2/resul ts? cond $=$ COVID-19\&term $=$ Favipiravir $\&$ cntry $=\&$ state $=\&$ city $=$ $\&$ dist $=\&$ Search $=$ Search. Accessed 10 Feb 2021

34. Hassanipour S, Arab-Zozani M, Amani B, Heidarzad F, Fathalipour M, Martinez-de-Hoyo R (2021) The efficacy and safety of Favipiravir in treatment of COVID-19: a systematic review and meta-analysis of clinical trials. Sci Rep 11(1):11022. https://doi. org/10.1038/s41598-021-90551-6

Publisher's note Springer Nature remains neutral with regard to jurisdictional claims in published maps and institutional affiliations. 